\title{
Study offeatures associated with death in children with severe malaria at a tertiary care hospital in Western India
}

\author{
Bharani $\mathbf{A}^{1}$ \\ ${ }^{1}$ Dr Anjali Bharani, Department of Pediatrics,Seth G. S. Medical College, KEM Hospital, Parel, Mumbai, \\ Maharashtra, India
}

Address for correspondence: Dr Anjali Bharani, Email: dr.anjalibharani@gmail.com

\begin{abstract}
Background:India contributes significantly to world malaria load and it accounts for $6 \%$ of the total malaria cases, $49 \%$ of the vivax malaria cases and $51 \%$ of vivax malaria deaths across the world.There is scarce informationabout predictors of mortality in children with severe malaria from India.Objectives:To study the factors associated with death in children with severe malaria at a tertiary care hospital in western India. Methods: A retrospective study was conducted at the pediatric department of a tertiary care hospital(Mumbai) over a threeyear period.Demographic data, clinical and laboratory findings of patients with slide-positive malaria were collected from hospital records. Children with any one of the manifestations of severe malariaas per WHO protocol were enrolled in the study.Univariate and multiple regression analysis were usedto identify major predictors of death like: 1) Severe Anemia, 2) Respiratory distress, 3) Multiple generalized convulsions, 4) Spontaneous bleeding, 5) Hemoglobinuria, 6) Impaired consciousness, 7) Jaundice, 8) Prostration, 9) Circulatory Collapse, 10) Pulmonary oedema. Results: Sixty-four subjectswere enrolled in the study. The case fatality rate was $20 \%$. Thirty five $(55 \%)$ patients presented with more than one predictor.The mortality rate was consistently high in patients having more than one predictor. Univariate analysis identified spontaneous bleeding (35\% mortality)and multiple convulsions (60\% mortality) as major predictors of death. Multivariate analysis showed no single factor emerged as a significant predictor of death.Conclusions: Spontaneous bleeding and multiple convulsions emerged as significant predictors of death during Univariate analysis. However no single factor emerged as significant predictor during multivariate analysis.
\end{abstract}

Key words: Severe malaria, Children, Mortality, Bleeding, Convulsions

\section{Introduction}

According to World Health Organization (WHO), in the year 2015, the global tally of malaria was 212 million new cases and 429000 deaths [1]. Malaria is widely rampant in India as it accounted for $6 \%$ of the total malaria cases, $49 \%$ of the vivax malaria cases and $51 \%$ of vivax malaria deaths across the world. Over 1 million malaria cases were reported in India in 2016 out of which 716213 were of falciparum and 331 died [2]. Indian study from Orissa showed that the mortality in cases with severe malaria was $12 \%$ [3].Various authors have described factors like respiratory distress, impaired consciousness, circulatory collapse, multi-organ

Manuscript received: $04^{\text {th }}$ September 2017

Reviewed: $10^{\text {th }}$ September 2017

Author Corrected: $15^{\text {th }}$ September 2017

Accepted for Publication: 22 ${ }^{\text {nd }}$ September 2017 dysfunction as significant in predicting mortality in severe malaria[3,4,5,6,7]. Studies have shown that delayed diagnosis was one of the important factors associated with death [8].Hence early identification of these risk factors may help in limiting the morbidity and mortality due to malaria. Also it is known that there may be major differences in the clinical manifestations of malaria at different ages and under different levels of endemicity. WHO guidelines are drawn from African experience which may not reflect the picture in our setup [4].Hence this study was conceived so as to identify the potential risk factors associated with death in cases with severe malaria among the pediatric patients presenting to a tertiary care centre in a metropolitan city in western India. 


\section{Material and Methods}

\section{Study Design and Setting:}

This retrospective study was conducted in the Department of Pediatrics in a university hospital in a large metropolitan city in western India over a threeyear period beginning January 2007.

\section{Inclusion Criteria}

Children aged 1 month -12 years admitted with features of severe malaria hospital with proven diagnosis of malaria (smear positive for malarial parasite on microscopic examination).

Severe malaria was diagnosed as presence of any one of the following features [9]:

1. Severe Anemia(Hemoglobin concentration $<5$ $\mathrm{gm} / \mathrm{dl})$

2. Respiratory distress(tachypnea, flaring of alae nasi, chest indrawing or deep breathing (acidotic breathing),

3. Multiple generalized convulsions(Two or more generalized convulsions in 24 hour),

4. Spontaneous bleeding,
5. Hemoglobinuria,

6. Impaired consciousness,

7. Jaundice,

8. Prostration (unable to stand, sit or feed),

9. Circulatory collapse,

10. Pulmonary edema (radiological).

\section{Exclusion Criteria}

Children discharged against medical advice.

Data Collection- Data was retrieved from the Medical Records Department. The following details were recorded, demographic data, chief complaints, clinical findings, results of investigations, treatment given and outcome (death/ survival).

Statistical methods- Univariate and Multiple regression analysis were used to evaluate possible association between different variables and morbidity and mortality in patients with severe malaria.

Ethics- The study was approved by the Institutional ethics committee.

\section{Results}

Sixty-four patients (boys: 37, girls: 27, M/F: 1.37:1) satisfied the WHO criteria for severe malaria and were included in the study. The mean age of the patients was $6.38 \pm 3.28$ years (Range: -0.08 to 12 years). Thirtynine $(61 \%)$ patients were above 5 years of age.Out of the 64 patients enrolled in the study, 13 (20\%) patients succumbed to death. Ten ( $77 \%)$ of these were above 5 years age group.

In our study, 35patientshad 2 or more manifestations, while 6 patients had 3 manifestations. The mortality rate was consistently high in patients having more than one predictor. Two of the twenty-nine patients (7\%) with one predictor died, whereas eight of the twenty-nine patients $(28 \%)$ with two predictors died. The mortality in patients with three predictors was very high $(50 \%)$, as three of the six patients with three predictors died.

The common predictors seen in the patients were severe anemia, spontaneous bleeding, circulatory collapse and impaired consciousness (Table 1).Common presentations of bleeding were petechiae, purpura, malenaor altered aspirates from nasogastric tube. Other manifestations like hematuria and hemoptysiswere rare. More than one third of our patients (39\%) had neurological involvement in the form of either impaired consciousness or multiple generalized convulsions or prostration. Seizures were found to be more frequent among under-five age group, (4 cases out of 7; not significant).

Also shown is the mortality associated with each predictor of severe malaria. The highest mortality rate was associated with presence of multiple generalized convulsions $(60 \%)$ followed by respiratory distress $(50 \%)$ and spontaneous bleeding (35\%) in that order.

The data was analyzed using Univariate regression model to find those factors that significantly contributed to mortality. It was seen that multiple convulsions and spontaneous bleeding were significant in predicting death.Very few cases were reported with manifestations like hemoglobinuria, jaundice, prostration, and pulmonary edema. 
Table-1: Prevalence of major clinical criteria of severe malaria and associated mortality(Univariate logistic regression analysis for all variables with death as the outcome measure)

\begin{tabular}{|c|c|c|c|c|}
\hline Sr.No. & Manifestations & $\begin{array}{c}\text { Prevalence } \\
\mathbf{n = 6 4}\end{array}$ & Mortality & P value \\
\hline 1 & Severe anemia & $26(40.62)$ & $2(7.69)$ & 0.051 \\
\hline 2 & Respiratory distress & $4(6.25)$ & $2(50.00)$ & 0.1274 \\
\hline 3 & Multiple generalized convulsions & $5(7.81)$ & $3(60.00)$ & $0.0216^{*}$ \\
\hline 4 & Spontaneous bleeding & $26(40.62)$ & $9(34.61)$ & $0.0186^{*}$ \\
\hline 5 & Hemoglobinuria & $1(1.56)$ & $0(0.00)$ & 0.6108 \\
\hline 6 & Impaired consciousness & $19(29.68)$ & $5(26.31)$ & 0.4379 \\
\hline 7 & Jaundice & $0(0.00)$ & $0(0.00)$ & - \\
\hline 8 & Prostration & $4(6.25)$ & $0(0.00)$ & 0.2970 \\
\hline 9 & Circulatory collapse & $20(31.25)$ & $6(30.00)$ & 0.1940 \\
\hline 10 & Pulmonary edema & $1(1.56)$ & $0(0.00)$ & 0.6108 \\
\hline
\end{tabular}

Figures in parentheses indicate percentages

*: statistically significant $(\mathrm{p}<0.05)$

Hyperparasitemia (Parasite index $>10 \%$; not an indicator of severe malaria as per WHO criteria) was present in 13 cases i.e. $20.3 \%$ cases. Out of them 3 had died. However, it was not a significant predictor of death $(\mathrm{P}=0.836)$. $\mathrm{P}$. falciparum malaria (40 patients) was more common than P. vivax (17 patients) followed by mixed infections (7 patients). Themortality in P. vivax cases was $29 \%$ (5 cases), whereas the mortality in P. falciparum cases was $18 \%$ ( 7 cases).

We used data of our Univariate model to include all of the possible predictors in the multiple regression analysis. Jaundice, Pulmonary Edema, Prostration, and Hemoglobinuria were excluded from this analysis because of very small number of patients in each group. Multivariate analysis showed that no single factor predicted death. On the contrary severe anemia was found to lower the mortality i.e. predictor for survival (Table 2).

Table 2: Major predictor multiple logistic regression model for malarial deaths in children

\begin{tabular}{|c|c|c|c|c|c|}
\hline & $\begin{array}{c}\text { Un-standardized } \\
\text { Coefficients Beta }\end{array}$ & Std. Error & $\begin{array}{c}\text { Standardized } \\
\text { Coefficients Beta }\end{array}$ & T & Sig. \\
\hline (Constant) & 0.431 & 0.489 & & 0.698 & 0.430 \\
\hline Anemia & 0.00472 & .0034 & 0.169 & 2.36 & $0.039^{*}$ \\
\hline Respiratory distress & 0.0398 & 0.0426 & 0.154 & 1.267 & 0.489 \\
\hline $\begin{array}{c}\text { Multiple Generalized } \\
\text { Convulsions }\end{array}$ & 0.187 & 0.165 & 0.123 & 1.032 & 0.304 \\
\hline Spontaneous Bleeding & 0.149 & 0.712 & 0.736 & 0.886 & 0.377 \\
\hline Hemoglobinuria & 0.0486 & 0.0359 & 0.071 & 0.863 & 0.389 \\
\hline Impaired consciousness & 0.0369 & 0.0423 & 0.812 & 1.102 & 0.272 \\
\hline Circulatory Collapse & 0.0589 & 0.060 & 0.354 & 0.139 & 0.890 \\
\hline
\end{tabular}

- Predictors: (Constant), Anemia, Respiratory Distress, Multiple Generalized Convulsions, Bleeding, Hemoglobinuria, Impaired consciousness andCirculatory Collapse.

- Dependent Variable: Patient Survival

\section{Discussion}

Malaria imposes great socio-economic burden on humanity and with six other diseases like diarrhea, HIV, tuberculosis, measles, and hepatitis and pneumonia accounts for $85 \%$ of Global infectious disease burden[8]. Even a century after the discovery of malaria transmission through mosquitoes in India by Sir Ronald Ross in 1897, malaria continues to be one of India's leading public health problems. 
Malaria is a public health problem in several parts of our country. About $95 \%$ population in the country resides in malaria endemic areas. Forty six percent of malarial cases are reported from people residing in tribal, hilly, difficult and inaccessible areaswhich contributes to only $8 \%$ of total population[10].The WHO has published guidelines for early identification of patients with severe malaria based on clinical and laboratory criteria[9]. Many studies have been published from various high and low transmission areas of Africa as it carries the greatest burden of the disease. But very few studies have been published from India to identify factors that contribute to mortality in children with severe malaria.

Patients who went discharge against medical advice were excluded from the study as no follow up of them was available.

The mortality in our study was $20 \%$ with highest mortality rate in age group 4-6 years and was comparatively lesser in below 4 years age group. Around $26(40.6 \%)$ cases had spontaneous bleeding at presentation. These patients required urgent supportive management in the form of platelet transfusions (given in 39 patients) and FFP transfusions (given in 13 patients) to prevent further deterioration. Out of these 26 patients, 9 (34.6\%) patients had succumbed to disease. The mortality due to spontaneous bleeding was significantly higher than a similar study done in Orissa where spontaneous bleeding was present in only $2.4 \%$ of the patients with a mortality of $3 \%$ only [3]. Upon Univariate analysis spontaneous bleeding emerged as a significant predictor of death. In most of the patients this was secondary to malaria induced severe thrombocytopenia while in others underlying deranged coagulation had led to it.

More than one third of our patients $(39 \%)$ had neurological involvement in the form of either impaired consciousness or multiple generalized convulsions or prostration. This was similar to the findings of Idro $\mathrm{R}$ et al from Kenya who found neurological involvement in children with malaria in $47.6 \%$ cases [11]. We found seizures to be more frequent among under-five age group, (4 cases out of 7). Similarly,Olanrewaju et alfound that children admitted with severe malaria below 5 years were significantly more prone to seizure [12]. In our study, multiple convulsions emerged as a significant predictor of death during Univariate analysis. These findings were similar to that, seen in a large study done in African children where the mortality in children significantly increased in those who had convulsions [5]. It is well known that cerebral malaria is secondary to the ability of P.falciparum to sequester in the deep vascular beds leading to impaired perfusion; hypoglycemia, hyperpyrexia that commonly occur in malaria also contribute to the neurological manifestations.

K.Maitland et al from Kenya highlighted that impaired perfusion was a significant predictor of deathin children with severe malaria [13]. In theirstudy, they found a mortality of $17.5 \%$ in those who presented with shock. Similarly, in a study conducted in Northern Ghana, Frank P. Mockehaupt et al reported circulatory collapse as the most significant predictor of death with a case fatality rate of $77.8 \%$ [6]. In our study, the children presenting with circulatory collapse had a mortality of $30 \%$ and however it was not a significant predictor of death. This may represent the difference in the health facilities provided to the children as ours is a tertiary care center with PICU facilities.

In malaria-endemic areas, malaria control is known to reduce childhood anemia. As per a review study based on community based interventions targeting malaria reduction, childhood anemia was found to be a useful indicator of the burden of malaria and of the progress in malaria control [14]. There are numerous mechanisms causing severe anemia like hemolysis, sequestration of erythrocytes in the spleen and other organs, and bone marrow suppression. In our study, severe anemia was a very common finding present in 26 patients $(40.6 \%)$, but it was associated with low mortality as only two (7.7\%) patients died. None of the patients with severe anemia as a sole risk factor died. Though it was statistically significant, it was not positively co-related with death and it was a predictor for survival. This indicates that mortality associated with other major predictors outweighs that due to severe anemia alone. Also, the mortality may be significantly decreased in severe anemia owing to the prompt availability of screened blood transfusions given to our patients [15].

In our study, respiratory distress was present in 4 cases (6.25\%). Out of these 4 patients 2 succumbed to their illness (mortality $50 \%$ ). This was not statistically significant in view of very small number of cases. But this 
highlights the greater mortality associated with this factor. Kevin Marsh et al who studied African children from Kenya found that respiratory distress was present in $13.7 \%$ of the patients with a mortality of $13.9 \%$ and was a major predictor of death [4]. They have suggested that respiratory distress be used as a simple bedside test to identify those children with malaria prone for highest risk of death. Respiratory distress in malaria is thought to develop secondary to multiple factors like acidosis due to impaired perfusion, cardiac failure due to severe anemia, or pulmonary edema and development of ARDS.

Prostration, jaundice and hemoglobinuria were seen in very few number of patients and none of them had any mortality.

When we looked at the microbiological aspect of fever, we found that $\mathrm{P}$ falciparum was the most common agent implicated followed by $\mathrm{P}$ vivax. However greater mortality was seen in patients suffering from $\mathrm{P}$ vivax malaria. This was also reported elsewhere [16].

As per the study done by Tripathy R. et al from Orissa in India respiratory distress, coma, multiple organ dysfunction and hyperparasitemia were found to be the major predictors of death during multivariate analysis [3]. However, in our study spontaneous bleeding and multiple convulsions were found to be significant predictors of death as per Univariate analysis but none of the predictors were found to be significant during multivariate analysis. This can be explained by the fact that spontaneous bleeding and multiple convulsions are predictive of death only because of their associations with other variables.

Table-3: Comparison of studies in children with severe malaria

\begin{tabular}{|c|c|c|c|c|}
\hline $\begin{array}{c}\text { Author, Year of } \\
\text { study, Country/ } \\
\text { Region } \\
\end{array}$ & $\begin{array}{c}\text { No of } \\
\text { subjects }\end{array}$ & $\begin{array}{c}\text { Mortality rate } \\
(\%)\end{array}$ & $\begin{array}{c}\text { Significant predictor } \\
\text { (Univariate) }\end{array}$ & $\begin{array}{l}\text { Significant predictor } \\
\text { (Multivariate) }\end{array}$ \\
\hline $\begin{array}{c}\text { Marsh K et al [4], } \\
\text { 1995; Kenya }\end{array}$ & 1844 & 3.5 & $\begin{array}{l}\text { Impaired consciousness, } \\
\text { Respiratory distress, } \\
\text { Hypoglycemia, Jaundice }\end{array}$ & $\begin{array}{c}\text { Impaired consciousness, } \\
\text { Respiratory distress, } \\
\text { Hypoglycemia, Jaundice }\end{array}$ \\
\hline $\begin{array}{c}\text { Mockenhaupt F. P. } \\
\text { et al[6], 2004; } \\
\text { Ghana }\end{array}$ & 290 & 11.2 & $\begin{array}{c}\text { Circulatory collapse, } \\
\text { Impaired consciousness, } \\
\text { Hypoglycemia, } \\
\text { Malnutrition, Respiratory } \\
\text { distress, Hyperlactatemia, } \\
\text { Hyperparasitemia }\end{array}$ & $\begin{array}{l}\text { Circulatory collapse, } \\
\text { Impaired consciousness, } \\
\text { Hypoglycemia, } \\
\text { Malnutrition }\end{array}$ \\
\hline $\begin{array}{c}\text { Seidlein LV et } \\
\text { al[5], 2010; African } \\
\text { countries }\end{array}$ & 5426 & 9.7 & $\begin{array}{l}\text { Base deficit, impaired } \\
\text { consciousness, elevated } \\
\text { blood urea, underlying } \\
\text { chronic illness }\end{array}$ & $\begin{array}{c}\text { Base deficit, impaired } \\
\text { consciousness, elevated } \\
\text { blood urea, underlying } \\
\text { chronic illness }\end{array}$ \\
\hline $\begin{array}{l}\text { AlTaiar A et al[7], } \\
\text { 2006; Yemen }\end{array}$ & 808 & 3.2 & $\begin{array}{c}\mathrm{BCS}<2 . \text {, Coma, female } \\
\text { sex, Hyperlactatemia }\end{array}$ & $\begin{array}{c}\text { BCS }<2 . \text {, Coma, female } \\
\text { sex, Hyperlactatemia }\end{array}$ \\
\hline $\begin{array}{c}\text { Tripathy R et al [3], } \\
\text { 2007; India }\end{array}$ & 374 & 12 & $\begin{array}{c}\text { Multiple organ dysfunction, } \\
\text { Hyperparasitemia, } \\
\text { Respiratory distress and } \\
\text { Coma }\end{array}$ & $\begin{array}{c}\text { Multiple organ } \\
\text { dysfunction, } \\
\text { Hyperparasitemia, } \\
\text { Respiratory distress and } \\
\text { Coma } \\
\end{array}$ \\
\hline $\begin{array}{l}\text { Our study, 2011; } \\
\text { India }\end{array}$ & 64 & 20 & $\begin{array}{l}\text { Multiple convulsions, } \\
\text { spontaneous bleeding }\end{array}$ & None \\
\hline
\end{tabular}

As we compare the various studies on severe malaria in children in India and abroad, we find that the significant predictors of mortality vary widely (Table 3). The disease pattern and the relative contribution of individual symptoms to mortality differ with endemicity, geographic location, access to health services, and age. However central nervous system involvement in the form of impaired consciousness or coma or multiple convulsions was a significant predictor common to all studies. Though severe malaria in children has been extensively studied in the heavily burdened African areas, similar studies giving the exact picture of this wide spread disease of public health importance is lacking from India [1].This study highlights the important clinical predictors of severe 
malaria from a large metropolitan city of western India and also shows the differences in the clinical picture of severe malaria in Indian children from Mumbai and other areas in India and abroad. Shortcoming of this study was its retrospective nature and small sample size.

\section{Conclusions}

The mortality rate in our study was $20 \%$. Falciparum malaria was responsible for majority of cases. However, patients with P vivax malariahad a greater mortality rate $(29.4 \%)$ when compared to P falciparum malaria (17.5 $\%)$. Spontaneous bleeding and multiple convulsions independently emerged as significant predictors of death as per the Univariateanalysis. In the multivariate analysis, no single factor emerged as significant predictor of death.

Despite availability of highly effective drugs, malaria still carries high risk of mortality. Early bed-side recognition, treatment and prompt referral of children with severe malaria presenting with these life-threatening symptoms will help bring down the mortality associated with this disease.Large scale prospective studies from India will help in analysing the accurate picture of the disease, to formulate better regional management strategies for effective management of this disease.

What this study adds?Spontaneous bleeding and multiple convulsions emerged as significant predictors of death in children with severe malaria as per the Univariate analysis

\section{Acknowledgements:}

The author would like to acknowledge Professor Dr. Sandeep B. Bavdekar who was instrumental in guiding this study and the Dean, Seth G. S. Medical College and. KEM Hospital for giving permission to conduct this study and publish this article

Funding: Nil, Conflict of interest: None initiated, Perission from IRB: Yes

\section{References}

1. World Health Organization. World Malaria Report 2016. Available from: http://www.who.int/malaria/publications/world-malariareport-2016/report/en/(last accessed on 10 July 2017

2. Ministry of Health and Family Welfare. National vector borne disease control program. Malaria.

[Internet]. 2017. Available from: http://nvbdcp.gov.in [last accessed on 8 July 2017].

3. Tripathy R, Parida S, Das L, Mishra D, Tripathy D, Das M, Chen H, Maguire J and Panigrahi P. Clinical Manifestations and Predictors of Severe Malaria in Indian Children. Pediatrics. 2007; 120(3): 454-60.

4. Marsh K, Forster D, Waruiru C, Mwangi I, Winstanley M, Marsh V, Newton C, Winstanley P, Warn P, Peshu $\mathrm{N}$, et al. Indicators of life-threatening malaria in African children. N Engl J Med. 1995 May 25;332(21):1399-404.

5.Seidlein LV, Olaosebikan R, Hendriksen IC, Lee SJ, Adedoyin OT, Agbenyega T et al. Predicting the Clinical Outcome of Severe Falciparum Malaria in African Children: Findings From a Large Randomized Trial. Clinical Infectious Diseases 2012; 54(8): 1080-90.

6. Mockenhaupt FP, Ehrhardt S, Burkhardt J, Bosomtwe SY, Laryea S, Anemana SD, Otchwemah RN, Cramer JP, Dietz E, Gellert S, Bienzle U. Manifestation and outcome of severe malaria in children in northern Ghana. Am J Trop Med Hyg. 2004 Aug;71(2):167-72. 
7. Al-Taiar A, Jaffar S, Assabri A, Al-Habori M, Azazy A, Al-Mahdi N, Ameen K, Greenwood BM, Whitty CJ. Severe malaria in children in Yemen: two site observational study. BMJ. 2006 Oct 21;333(7573):827.

8. Kumar A, Valecha N, Jain T, Dash AP. Burden of malaria in India: retrospective and prospective view. Am J Trop Med Hyg. 2007 Dec;77(6 Suppl):69-78.

9. World Health Organization: Severe Falciparum Malaria. World Health Organization, communicable disease cluster. Trans R Soc Trop Med Hyg 2000; 94(suppl 1): S1- S90.

10. Sharma RK, Thakor HG, Saha KB, Sonal GS, Dhariwal AC, Singh N. Malaria situation in India with special reference to tribal areas. Indian J Med Res. 2015 May;141(5):537-45.

11. Idro R, Ndiritu M, Ogutu B, Mithwani S, Maitland K, Berkley J, Crawley J, Fegan G, Bauni E, Peshu N, Marsh K, Neville B, Newton C. Burden, features, and outcome of neurological involvement in acute falciparum malaria in Kenyan children. JAMA. 2007 May 23;297(20):2232-40.

12. Olanrewaju WI, Johnson AW. Malaria in children in Ilorin, Nigeria. East Afr Med J. 2001 Mar;78(3):131-4.

13. Maitland K, Levin M, English M, Mithwani S, Peshu N, Marsh K, Newton CR. Severe P. falciparum malaria in Kenyan children: evidence for hypovolaemia. QJM. 2003 Jun;96(6):427-34.

14. Korenromp EL, Armstrong-Schellenberg JR, Williams BG, Nahlen BL and, Snow RW. Impact of malaria control on childhood anemia in Africa- a quantitative review. Trop Med Int Health 2004; 9(10):1050-65.

15. Obonyo CO, Steyerberg EW, Oloo AJ, Habbema JD. Blood transfusions for severe malaria-related anemia in Africa: a decision analysis. Am J Trop Med Hyg. 1998 Nov;59(5):808-12.

16. Yadav D, Chandra J, Aneja S, Kumar V, Kumar P, Dutta AK. Changing profile of severe malaria in north Indian children. Indian J Pediatr. 2012 Apr;79(4):483-7. doi: 10.1007/s12098-011-0603-x. Epub 2011 Nov 18.

\section{How to cite this article?}

Bharani A, Study offeatures associated with death in children with severe malaria at a tertiary care hospital in Western India. J PediatrRes. 2017;4(09):559-565.doi:10.17511/ijpr.2017.i09.04. 